\title{
ANALISIS PERBANDINGAN NILAI SIGNAL TO NOISE RATIO (SNR) PADA PEMERIKSAAN MRI ANKLE JOINT DENGAN MENGGUNAKAN QUAD KNEE COIL DAN FLEX/MULTIPURPOSE COIL
}

\section{COMPARATIVE ANALYSIS OF THE VALUE OF SIGNAL TO NOISE RATIO (SNR) AT MRI ANKLE JOINT EXAMINATION USING QUAD KNEE COIL AND FLEX/MULTIPURPOSE COIL}

\author{
Ahda Nur Arifah ${ }^{1)}$, Yeti Kartikasari ${ }^{2)}$, Emi Murniati ${ }^{3)}$ \\ ${ }^{1,2,3)}$ Health Polytechnics of Semarang-Indonesia \\ e-mail : ahda.trr@gmail.com
}

\begin{abstract}
Background : Research on the difference comparison the value of Signal To Noise Ratio (SNR) at MRI Ankle Joint examination using Quad Knee Coil and Flex/Multipurpose Coil at the hospital's radiology installation Telogorejo Semarang. Quad knee coil is a volume coil, is a coil that can act as a transmitter and receiver at the same RF signal (transreceiver). Flex / Multipurpose Coil is a surface coil which has a high SNR for a superficial examination (a small organ). The purpose of this research is to know comparison the value of signal to noise ratio (SNR) and higher the value of signal to noise ratio (SNR) at MRI Ankle Joint examination using Quad Knee Coil and Flex / Multipurpose Coil.

Method : This type of research is quantitative experimental approach. The research data which 6 samples. Rate includes images subjectively talocalcaneal interosseous ligament, talocrural joint, subtalar joint, the calcaneus, tibia, talus, and the Achilles tendon. Then the results of the data in Paired T-Test tested.

Results : Test results that there are differences in comparison the value of signal to noise ratio (SNR) at MRI Ankle Joint examination using Quad Knee Coil and Flex / Multipurpose Coil which has a p-value / sig for all of 0.002, and each criterion that have talocalcaneal interoseous ligament $\mathrm{p}$ value 0.026 , talocrural joint $\mathrm{p}$ value 0.017 , subtalar joint $\mathrm{p}$ value 0.001 , calcaneus $\mathrm{p}$ value 0.002 , tibia $\mathrm{p}$ value 0.003 , talus $\mathrm{p}$ value 0.006 , and achilles tendon $\mathrm{p}$ value 0.012 . This is in accordance with the calculated average value SNR on the use of Quad Knee Coil is higher at 110.67 because the coil acts as transreceiver and has two preamplifier so as to improve the SNR

Conclusion : There is a differences in comparison the value of Signal To Noise Ratio (SNR) at MRI Ankle Joint examination using Quad Knee Coil and Flex / Multipurpose Coil.
\end{abstract}

Keywords : Signal to Noise Ratio (SNR), Quad Knee Coil, Flex / Multipurpose Coil

\section{PENDAHULUAN}

MRI (Magnetic Resonance Imaging) merupakan salah satu modalitas imejing diagnostik yang dapat menghasilkan irisan anatomi tubuh secara multiplanar dengan kontras pada jaringan lebih baik daripada CT-Scan. Sehingga MRI sangat baik digunakan untuk mendeteksi suatu lesi pada jaringan lunak. Dengan manipulasi parameter MR maka akan dihasilkan sekuen yang baik dalam menilai patologi tertentu (Blink, 2004). Menurut Westbrook dkk (2011), MRI menggunakan medan magnet yang kuat menyesuaikan magnetisasi atom hidrogen di dalam tubuh. Radiofrekuensi (RF) bidang dipakai untuk mengubah alignment magnetisasi ini, sehingga menghasilkan medan magnet berputar (spin) yang dapat dideteksi dengan coil penerima atau receiver.

Ahda : Analisis Perbandingan Nilai Signal...
Menurut Kartawiguna (2015), tujuan pemeriksaan MRI adalah untuk mendapatkan citra dengan informasi diagnostik dalam waktu pemeriksaan yang tidak terlalu lama. Untuk mencapai tujuan tersebut, harus dipahami apa yang menyebabkan sebuah citra sangat baik kualitasnya. Kualitas citra MRI yang optimal ditentukan oleh tiga karakteristik, yaitu spatial resolution, signal to noise ratio (SNR), contras to noise ratio (CNR). Spatial resolution merupakan kemampuan untuk membedakan antara dua titik secara terpisah dan jelas, berfungsi untuk melihat ketajaman pada gambar dalam mengidentifikasi obyek yang kecil. SNR yaitu perbandingan antara besarnya amplitudo sinyal dengan amplitudo noise yang mana nilai SNR tersebut digunakan sebagai kriteria untuk menentukan kualitas citra. CNR adalah perbedaan SNR antara organ yang saling 
berdekatan. CNR yang baik dapat menunjukkan perbedaan daerah yang patologis dan daerah sehat.

Signal to noise ratio (SNR) berpengaruh terhadap kualitas citra MRI yang dihasilkan karena kenaikan nilai SNR diikuti dengan peningkatan kualitas gambar. SNR yang tinggi bisa dimanfaatkan untuk menghasilkan gambar dengan spatial resolution yang baik karena SNR di pengaruhi oleh kekuatan medan magnet. Medan magnet yang lebih kuat akan meningkatkan longitudinal magnetization karena lebih banyak proton yang sejajar (paralel) dengan sumbu utama dari medan magnet sehingga sulit diukur sinyalnya. Pemilihan radiofrequency $(\mathrm{RF})$ coil sangat diperlukan untuk merubah arah induksi magnetnya sehingga bisa diukur sinyalnya pada organ yang diperiksa dan SNR meningkat (Kartawiguna, 2015).

Menurut Kartawiguna (2015), untuk mendapatkan kualitas citra yang baik pada radiofrequency (RF) coil maka dirancang coil sesuai dengan pemeriksaan dengan berbagai tipe ukuran agar dapat disesuaikan dengan bagian tubuh yang diperiksa. Terdapat coil sebagai pemancar (body coil) dan sebagai penerima (local coil), namun ada juga yang berfungsi sebagai pemancar sekaligus penerima sinyal RF. Menurut Zhou (2006), beberapa jenis RF coil pada pemeriksaan MRI yaitu Surface Coil (contohnya shoulder coil, neck coil dan flex/multipurpose coil), Volume Coil (contohnya knee coil dan head coil), Phased Array Coil (contohnya body array coil dan spine array coil), dan Quadrature Coil. Salah satu penggunaan RF coil pada pemeriksaan MRI yaitu ankle joint.

Ankle joint merupakan salah satu bagian sendi pada tubuh yang berada diatas kaki, berfungsi untuk menumpu badan sehingga memiliki resiko cidera yang cukup besar. Pemeriksaan ankle joint ini dapat dilakukan dengan pemeriksaan radiografi konvensional dan CT-Scan, namun untuk menampakkan citra yang lebih informatif, maka pemeriksaan MRI lebih baik dari modalitas lain. Pemeriksaan ankle joint menggunakan MRI dapat dilakukan dengan aman, tanpa radiasi, dan dapat dilihat dari potongan axial, sagital, coronal tanpa mengubah posisi pasien. Pada pemeriksaan MRI ankle joint di salah satu Instalasi Radiologi, menggunakan quad knee coil yang merupakan volume coil sekalipun Instalasi tersebut terdapat flex/multipurpose coil yang bisa digunakan untuk pemeriksaan persendian termasuk ankle joint. Namun belum ada penelitian tentang pengaruh perbedaan penggunaan coil tersebut terhadap nilai SNR.

Berdasarkan hal tersebut maka penulis tertarik untuk melakukan penelitian dengan tujuan untuk mengetahui hasil penggunaan coil yang berbeda terhadap nilai SNR, khususnya pada irisan sagital karna lebih informatif dalam menampakkan skeleton, persendian, ligament dan tendon yang diinginkan praktisi radiologi.

\section{METODE}

Jenis penelitian yang digunakan adalah penelitian kuantitatif dengan pendekatan eksperimen. Variabel yang digunakan dalam penelitian adalah variabel bebas yaitu Quad
Knee Coil dengan Flex/Multipurpose Coil, variabel terikat yaitu Signal to Noise Ratio (SNR). Serta variabel terkontrol yaitu sekuen, time repetation (TR), time echo (TE), field of view (FOV), slice thickness, matrix, flip angel, bandwith, Number of Excitation (NEX), irisan/potongan, dan region of interest (ROI). Penelitian ini dilakukan pada bulan Desember 2016 sampai dengan Januari 2017 di bagian MRI Instalasi Radiologi Rumah Sakit Telogorejo Semarang. Populasi dalam penelitian ini adalah seluruh pasien dengan pemeriksaan MRI Ankle Joint dan sampel pada penelitian ini 6 orang pasien.

\section{Prosedur penelitian}

Pemeriksaan dilakukan dengan sekuen T2 spin echo menggunakan dua jenis coil RF yang berbeda, yaitu Quad Knee Coil dan Flex/Multipurpose Coil dilakukan pada obyek Ankle Joint sebanyak 6 pasien, dan hasil citra MRI Ankle Joint diambil dari potongan sagittal,Parameter pada MRI Siemens Magnetom Avanto 1,5 Tesla yang dilakukan pada penelitian ini yaitu :

\begin{tabular}{clc}
\multicolumn{3}{c}{ Tabel 1. Parameter Pemeriksaan MRI Ankle Joint } \\
\hline No. & \multicolumn{1}{c}{ Parameter } & Nilai \\
\hline 1. & Sekuen & T2 Spin Echo \\
2. & Potongan & Sagital \\
3. & TR & $3500 \mathrm{~ms}$ \\
4. & TE & $74 \mathrm{~ms}$ \\
5. & FOV & $350 \mathrm{~mm}$ \\
6. & Slice Thickness & $3 \mathrm{~mm}$ \\
7. & Matrix & $256 \times 205$ \\
8. & Flip Angle & $20^{\circ}$ \\
9. & Bandwidth & $20 \%$ \\
10. & NEX & 2 \\
11. & ROI & 0.00201
\end{tabular}

Citra MRI Ankle Joint diberikan Region of Interest (ROI) sekecil mungkin pada Talocalcaneal Interosseous Ligament, Talocrural Joint, Subtalar Joint, Calcaneus, Tibia, Talus dan Achilles Tendon. Kemudian untuk noise, yang di ROI adalah daerah bebas diluar obyek ankle joint. Setelah data terkumpul, diukur nilai Signal to Noise Ratio (SNR) pada penggunaan Quad Knee Coil dan Flex/Multipurpose Coil untuk setiap obyek anatomi yang ditentukan. Data hasil perhitungan kemudian diolah dengan uji statistik SPSS. Berikut rumus perhitungan Signal to Noise Ratio (SNR), yaitu :

$$
\mathrm{SNR}=\frac{\text { signal }}{\text { noise }}
$$

Sampel pada penelitian ini berpasangan. Analisis data dilakukan dengan menggunakan uji statistik Paired T-Test, yang sebelumnya di uji normalitas karena berupa data numerik dengan skala rasio. Pada analisis statistik ini ditetapkan tingkat kepercayaan (level of significance) dengan nilai $\alpha=0,05$. Ha 
diterima apabila $\rho$ value $<0,05$, yang berarti ada perbedaan perbandingan nilai Signal to Noise Ratio (SNR) antara penggunaan Quad Knee Coil dengan Flex/Multipurpose Coil pada pemeriksaan MRI Ankle Joint. Ho ditolak apabila $\rho$ value $>0,05$, yang berarti tidak ada perbedaan perbandingan nilai Signal to Noise Ratio (SNR) antara penggunaan Quad Knee Coil dengan Flex/Multipurpose Coil pada pemeriksaan MRI Ankle Joint.

\section{HASIL}

Penelitian perbandingan nilai signal to noise ratio (SNR) pada pemeriksaan MRI ankle joint dengan menggunakan quad knee coil dan flex/multipurpose coil dan dilakukan dengan sampel yang terdiri dari 6 orang pasien dengan menggunakan MRI Siemens Magnetom Avanto 1,5 Tesla. Dimana terdapat 6 sampel berumur antara 20 tahun sampai dengan 30 tahun dan berjenis kelamin perempuan dan laki-laki.

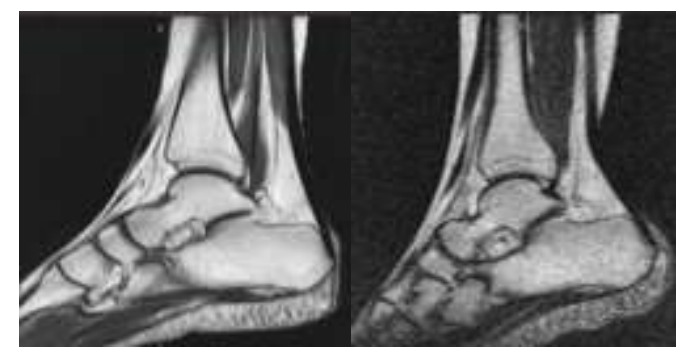

(A)

(B)

Gambar 1. (A) Citra MRI Ankle Joint Dengan Quad Knee Coil.

(B) Citra MRI Ankle Joint Dengan Flex/Multipurpose Coil

Perhitungan nilai SNR dilakukan pada masing-masing organ yang ada pada citra, antara lain SNR talocalcaneal interoseous ligament, SNR talocrural joint, SNR subtalar joint, SNR calcaneus, SNR tibia, SNR talus, dan SNR achilles tendon. Perhitungan nilai SNR dimulai dengan menempatkan ROI sekecil mungkin $\left( \pm 0,00201 \mathrm{~cm}^{2}\right)$ pada daerah talocalcaneal interoseous ligament (TIL), talocrural joint (TJ), subtalar joint (STJ), calcaneus (C), tibia (Tib), talus, dan achilles tendon sebanyak satu buah dalam satu organ, kemudian dibandingkan dengan nilai standar deviasi (SD) yang diletakkan pada daerah background noise diluar area obyek.

Perbandingan Nilai Signal To Noise Ratio (SNR) Pada Pemeriksaan MRI Ankle Joint Dengan Menggunakan Quad Knee Coil Dan Flex/Multipurpose Coil

Tabel 2. Nilai ROI dari koil radiofrekuensi (RF) dan Hasil Pengukuran SNR

\begin{tabular}{|c|c|c|c|c|c|c|c|c|c|}
\hline \multirow{2}{*}{$\begin{array}{l}c \\
0 \\
1 \\
\text { L }\end{array}$} & \multirow{2}{*}{$\begin{array}{l}\mathbf{T} \\
\mathrm{A} \\
\mathrm{s} \\
\mathrm{I} \\
\mathrm{E} \\
\mathrm{N}\end{array}$} & \multicolumn{7}{|c|}{ Nilai SNR } & \multirow{2}{*}{$\begin{array}{c}\text { Rata- } \\
\text { rata } \\
\text { SNR }\end{array}$} \\
\hline & & TIL & TJ & STJ & C & $T B$ & Tal & $A T$ & \\
\hline $\mathbf{Q}$ & 1 & 81.82 & 18.04 & 33.94 & 200.2 & 189.81 & 142.28 & 2.74 & 95.55 \\
\hline D & 2 & 23.49 & 11.83 & 27.24 & 97.82 & 94.55 & 85.12 & 7.32 & 49.62 \\
\hline $\mathbf{K}$ & 3 & 37.89 & 51.63 & 51.22 & 326.79 & 182.31 & 171.40 & 10.64 & 118.84 \\
\hline $\mathrm{N}$ & 4 & 29.15 & 32.26 & 35.09 & 276.14 & 129.65 & 240.62 & 9.45 & 107.48 \\
\hline $\mathbf{E}$ & 5 & 133.44 & 29.57 & 64.54 & 355.67 & 322.42 & 392.01 & 9.9 & 186.79 \\
\hline $\mathbf{E}$ & 6 & 37.82 & 72.95 & 53.25 & 198.81 & 179.74 & 193.36 & 4.58 & 105.79 \\
\hline & 1 & 0.995 & 3.197 & 3,46 & 12.38 & 9.26 & 3.95 & 2.24 & 5.07 \\
\hline $\mathbf{F}$ & 2 & 3.27 & 4.71 & 6.12 & 12.96 & 10.2 & 6.5 & 2.49 & 6.61 \\
\hline L & 3 & 3.38 & 2.58 & 1.45 & 20.47 & 10.45 & 8.29 & 4.06 & 7.24 \\
\hline $\begin{array}{l}\mathbf{E} \\
\mathbf{X}\end{array}$ & 4 & 0.64 & 2.2 & 1.49 & 5.99 & 7.42 & 3.66 & 1.31 & 3.24 \\
\hline & 5 & 0.84 & 0.94 & 1.30 & 5.65 & 5.76 & 4.31 & 0.78 & 2.8 \\
\hline & 6 & 2.16 & 225 & 3.08 & 10.7 & 9.39 & 10.9 & 2.1 & 5.8 \\
\hline
\end{tabular}

Berdasarkan tabel 2, dari data yang telah didapatkan kemudian diolah dan dianalisa dengan uji statistik menggunakan program SPSS. Hasil perhitungan SNR berupa data numerik dengan skala rasio. Uji normalitas data harus dilakukan terlebih dahulu untuk mengetahui data berdistribusi normal atau tidak.

Tabel 3. Hasil Uji Normalitas Data

\begin{tabular}{cccc}
\hline Variabel & Anatomi & $p$ value/sig & Makna \\
\hline & $\begin{array}{c}\text { Talocalcaneal } \\
\text { Interoseous } \\
\text { Ligament }\end{array}$ & 0,064 & Normal \\
& Talocrural & & \\
SNR Quad Knee & Joint & 0.598 & Normal \\
Coil & Subtular Joint & 0,587 & Normal \\
& Calcaneus & 0.749 & Normal \\
& Tibia & 0.306 & Normal \\
& Talus & 0.522 & Normal \\
& Achilles tendon & 0.392 & Normal \\
& Nalocalcaneal & & \\
& interoseus & 0.147 & Normal \\
& Ligament & & \\
Talocrural & 0.768 & Normal \\
SNR & Joint & Normal \\
& Subtular Joint & 0.119 & Normal \\
Calcaneus & 0.447 & Normal \\
& Tibia & 0.295 & Normal \\
& Talus & 0.291 & Normal \\
& Achilles & 0.711 & Normal \\
& tendons & &
\end{tabular}

Berdasarkan tabel 3, diperoleh signifikasi SNR pada MRI Ankle Joint dengan menggunakan Quad Knee Coil dan Flex/Multipurpose Coil >0.05, sehingga dapat disimpulkan bahwa data berdistribusi normal. Sehingga selanjutnya di analisis data dengan menggunakan uji statistic Paired T-Test. 
Tabel 4. Hasil Uji Statistik Paired T-Test SNR Keseluruhan

\begin{tabular}{ccc}
\hline Variabel & $p$ value/sig & Makna \\
\hline SNR Quad Knee Coil & 0.002 & Ada Beda \\
\hline SNR Flex/Multipurpose Coil & & \\
\hline
\end{tabular}

Berdasarkan tabel 4, diperoleh hasil uji statistik yang memiliki $p$ value/sig bernilai 0.002 yang artinya $<0.05$ atau kurang dari 0.05. Sehingga dapat disimpulkan bahwa pada pemeriksaan MRI Ankle Joint, nilai SNR pada penggunaan Quad Knee Coil dan Flex/Multipurpose Coil memiliki perbedaan yang signifikan.

Berdasarkan uji Paired T-Test pada tabel 5 tampak ada perbedaan yang signifikan penggunaan Quad Knee Coil dan Flex/Multipurpose Coil pada pemeriksaan MRI Ankle Joint untuk setiap anatomi. Adapun hasil pengujian Paired T-Test untuk setiap anatomi yaitu $p$ value talocalcaneal interoseous ligament $0.026, p$ value talocrural joint $0.017, p$ value subtalar joint $0.001, p$ value calcaneus 0.002 , $p$ value tibia $0.003, p$ value talus 0.006 , dan $p$ value achilles tendon 0.012 .

Tabel 5. Hasil Uji Statistik Paired T-Test SNR Per Kriteria Anatomi

\begin{tabular}{cc}
\hline Kriteria & p value \\
\hline Talocalcaneal Interoseous & 0.026 \\
Ligament & 0.017 \\
Talocrural Joint & 0.001 \\
Subtalar Joint & 0.002 \\
Calcaneus & 0.003 \\
Tibia & 0.006 \\
Talus & 0.012 \\
Achilles Tendon
\end{tabular}

Tabel 6. Hasil Perhitungan Nilai Rata-Rata SNR

\begin{tabular}{ccc}
\hline \multirow{2}{*}{ Pasien } & $\begin{array}{c}\text { SNR Quad Knee } \\
\text { Coil }\end{array}$ & $\begin{array}{c}\text { SNR } \\
\text { Flex/Multipurpose } \\
\text { Coil }\end{array}$ \\
\hline 1 & 95.55 & 5.07 \\
2 & 49.62 & 6.61 \\
3 & 118.84 & 7.24 \\
4 & 107.48 & 3.24 \\
5 & 186.79 & 2.8 \\
6 & 105.79 & 5.8 \\
\hline RATA- & 110.67 & 5.13 \\
RATA & & \\
\hline
\end{tabular}

Nilai Signal To Noise Ratio (SNR) Yang Lebih Tinggi Pada Pemeriksaan MRI Ankle Joint Dengan Menggunakan Quad Knee Coil Dan Flex/Multipurpose Coil
Berdasarkan tabel 6, menunjukkan nilai SNR tertinggi didapatkan dari penggunaan Quad Knee Coil yaitu 186.79, sedangkan nilai SNR terendah didapatkan dari penggunaan Flex/Multipurpose Coil yaitu 2.8. Nilai rata-rata SNR pada penggunaan Quad Knee Coil yaitu 110.67, dan nilai rata-rata SNR pada penggunaan Flex/Multipurpose Coil yaitu 5.13. Dapat disimpulkan bahwa Quad Knee Coil memiliki nilai rata-rata SNR lebih tinggi jika dibandingkan dengan Flex/Multipurpose Coil. Hal tersebut menunjukkan bahwa citra yang dihasilkan pada penggunaan Quad Knee Coil lebih baik daripada penggunaan Flex/Multipurpose Coil pada pemeriksaan MRI Ankle Joint.

\section{DISKUSI}

Berdasarkan data hasil uji statistik SNR keseluruhan, memiliki $\mathrm{p}$ value/sig bernilai 0.002 yang artinya $<0.05$ atau kurang dari 0.05. dari hasil uji statistik tersebut dapat disimpulkan bahwa hasil uji statistik SNR memiliki p value $<0.05$ sehingga Ha diterima dan Ho ditolak. Jika Ha diterima maka ada perbedaan perbandingan nilai Signal To Noise Ratio (SNR) pada pemeriksaan MRI Ankle Joint dengan menggunakan Quad Knee Coil dan Flex/Multipurpose Coil.

Perbedaan SNR yang signifikan, dapat dilihat juga dari $p$ value per anatomi antara penggunaan Quad Knee Coil dan Flex/Multipurpose Coil yaitu $p$ value talocalcaneal interoseous ligament $0.026, p$ value talocrural joint $0.017, p$ value subtalar joint $0.001, p$ value calcaneus $0.002, p$ value tibia $0.003, p$ value talus 0.006 , dan $p$ value achilles tendon 0.012. Dari hasil uji statistik tersebut dapat disimpulkan bahwa untuk SNR per kriteria anatomi memiliki perbedaan perbandingan nilai Signal To Noise Ratio (SNR) pada pemeriksaan MRI Ankle Joint dengan menggunakan Quad Knee Coil dan Flex/Multipurpose Coil. Perbedaan nilai SNR yang dihasilkan ini disebabkan karena Quad Knee Coil dan Flex/Multipurpose Coil merupakan jenis coil yang berbeda. Quad knee coil merupakan koil jenis volume coil, sedangkan Flex/Multipurpose Coil merupakan koil jenis surface coil atau koil permukaan (Zhou, 2006). Menurut Zhou (2006), volume coil merupakan koil yang dapat berperan sebagai pemancar RF sekaligus dan penerima sinyal sehingga sering disebut transreceiver. Keuntungan volume coil yaitu merupakan koil yang memiliki dua preamplifier (penerima dua sinyal) yang mendapatkan phase $90^{\circ}$ yang berbeda, sehingga dapat meningkatkan SNR dan mengurangi pulse power sampai setengahnya. Keuntungan yang lainnya yaitu menghasilkan homogenitas yang baik dibanding semua koil. Kekurangan dari koil ini adalah ukurannya besar sehingga tidak dapat menyesuaikan obyek yang diperiksa karena volume coil mengelilingi seluruh anatomi yang diperiksa.

Menurut Westbrook dkk (2011), surface coil pada umumnya berbentuk loop yang ditempatkan didekat obyek (sumber sinyal). Keuntungan dari koil ini yaitu memiliki SNR yang tinggi untuk pemeriksaan superficial (organ yang kecil), karena letaknya yang dekat dengan obyek dan jangkauannya 
hanya disekeliling lingkaran area koil. Selain itu strukturnya flexibel sesuai dengan obyek yang diperiksa. Menurut Zlatkin (2003), kekurangan dari surface coil yaitu memiliki luas atau cakupan area (FOV) yang kecil, penerimaan sinyal kecil yang menyebabkan timbulnya artefak susceptibility dan posisi koil terhadap pasien kurang nyaman.

Berdasarkan teori yang telah dikemukakan, terdapat kesesuaian dengan hasil penelitian yang menggunakan metode statistik. Terdapat perbedaan SNR yang dihasilkan pada pemeriksaan MRI Ankle Joint antara penggunaan Quad Knee Coil dan Flex/Multipurpose Coil. Hal tersebut dikarenakan Quad knee coil merupakan jenis volume coil yang memiliki dua preamplifier (penerima dua sinyal) sehingga SNR meningkat dan menghasilkan homogenitas yang baik. Sedangkan flex/multipurpose coil dapat menghasilkan SNR yang tinggi namun hanya di superficial (pada organ kecil) dan cakupan area atau luas (FOV) yang kecil. Karena ankle joint terdiri dari organ yg kecil namun FOVnya luas. Hal tersebut yang menimbulkan noise yang tinggi pada citra MRI Ankle Joint.

Berdasarkan hasil perhitungan nilai rata-rata SNR, Quad Knee Coil menunjukkan citra MRI Ankle Joint yang lebih baik dibandingkan Flex/Multipurpose Coil. Dalam hasil perhitungan tersebut dapat dilihat bahwa nilai rata-rata SNR pada penggunaan Quad Knee Coil adalah 110.67 dan nilai rata-rata SNR pada penggunaan Flex/Multipurpose Coil adalah 5.13. Hasil perhitungan tersebut menunjukkan bahwa Quad Knee Coil memiliki SNR yang lebih tinggi dibandingkan Flex/Multipurpose Coil.

Penggunaan Quad Knee Coil lebih tepat dibandingkan dengan penggunaan Flex/Multipurpose Coil karena dapat menghasilkan citra MRI dengan kualitas yang lebih baik jika dilihat dari nilai SNR yang dihasilkan. Hal ini disebabkan karena kenaikan SNR diikuti dengan peningkatan kualitas citra (Ness-Aiver, 2003). Selain itu menurut Westbook dkk (2011), penggunaan koil radiofrequency (RF) yang sesuai dengan obyek yang akan diperiksa merupakan salah satu faktor yang mempengaruhi jumlah sinyal yang diterima termasuk nilai SNR. Seperti pada pemeriksaan MRI Ankle Joint, pemilihan koil RF harus disesuaikan, karena jika menggunakan Flex/Multipurpose Coil pasien kurang nyaman dan terjadi space atau jarak antara organ dengan koil meskipun bentuknya flexibel. Diharapkan untuk penelitian selanjutnya pada Flex/Multipurpose Coil diteliti untuk bagian organ superficial, cakupan area atau luas (FOV) yang digunakan lebih kecil dan antara organ yang diperiksa dengan koil tidak terjadi space atau jarak.

\section{SIMPULAN}

Berdasarkan data hasil uji statistik SNR, terdapat perbedaan perbandingan nilai signal to noise ratio (SNR) pada pemeriksaan MRI Ankle Joint dengan menggunakan Quad Knee Coil dan Flex/Multipurpose Coil yang memiliki $p$ value/sig keseluruhan bernilai 0.002, dan hasil uji statistik untuk setiap anatomi yaitu $p$ value talocalcaneal interoseous ligament 0.026, $p$ value talocrural joint $0.017, p$ value subtalar joint $0.001, p$ value calcaneus 0.002 , $p$ value tibia 0.003 , p value talus 0.006 , dan $p$ value achilles tendon 0.012 , maka hasil uji statistik SNR memiliki $p$ value $<0.05$ sehingga Ha diterima dan Ho ditolak.

Hasil perhitungan nilai rata-rata SNR pada penggunaan Quad Knee Coil adalah 110.67 dan nilai rata-rata SNR pada penggunaan Flex/Multipurpose Coil adalah 5.13. Hasil perhitungan tersebut menunjukkan bahwa Quad Knee Coil memiliki SNR yang lebih tinggi dibandingkan Flex/Multipurpose Coil karena Quad Knee Coil merupakan koil yang dapat berperan sebagai pemancar RF sekaligus dan penerima sinyal (transreceiver) dan memiliki dua preamplifier (penerima dua sinyal) sehingga dapat meningkatkan SNR.

\section{DAFTAR PUSTAKA}

Bitar, Richard, et al. 2006. MR Pulse Sequences: What Every Radiologist Wants to Know but is Afraid to Ask, RSNA, Volume 26, Number 2. Diakses tanggal 28 Agustus 2016 pukul 23.01

Blink, Evert J. 2004. MRI : Physics, http://www.mri-physics.net. Diakses tanggal 16 September 2016 pukul 00.15 WIB

Budiman, Arif. 2011. Analisis perbandingan nilai signal to noise ratio (SNR) dan informasi anatomi antara penggunaan extremity coil dan flex coil pada pemeriksaan MRI knee joint. Poltekkes Kemenkes Semarang.

Kuperman, Vadim. 2000. MRI Physical Principles and Applications. Academic Press : USA.

Kartawiguna, Daniel. 2015. Tomografi Resonansi Magnetik Inti: Teori Dasar, Pembentukan Gambar dan Instrumentasi Perangkat Kerasnya. Yogyakarta

Moeler, M.D Torsen B; Reif, M.D Emil. 2003. MRI Parameters and Positioning. Thimes : New York.

Moeler, M.D Torsen B; Reif, M.D Emil. 2007. Pocket Atlas of Sectional Anatomy. Thimes : New York.

Mc.Robbie, Donal et al. 2006. MRI From Picture to Proton, Second Edition. Cambridge University Press : New York.

Ness-Aiver. 2003. All you really need to know about MRI Physics. Maryland Medical Center : USA.

Setiawan, I Gede Dedi. 2011. Analisis perbandingan informasi anatomi pada citra MRI wrist joint dengan menggunakan koil GP Flex dan quad knee pada pemeriksaan MRI Wrist Joint. Semarang. Poltekkes Kemenkes Semarang.

Walden. 2000. Bones and Joints of the ankle. Wymondham. http://www.sportsinjuryclinic.net/anatomy/ankle-anatomy. Diakses tanggal 24 Agustus 2016 pukul 02.29 WIB

Weishaupth, D. Kochil, VD. Marincek, B. 2006. How MRI Work?. Spinger : Germany.

Westbrook, Catherine. Roth, Carolyn Kaut. Talbot, John. 2011. MRI in Practice. Fourth Edition. Blackwell Science Ltd. : United Kingdom

Yip, Kevin. 2012. Ankle Spained. Singapore, http://www.orthopaedicsurgeon. com.sg/patients-education/ankle/ankle-sprained/. Diakses tanggal 16 September 2016 pukul 22.00 WIB

Zhou, Anqi. 2006. RF Coils in MRI, http://ric.uthscsa.edu/personalpages /lancaster. Diakses tanggal 30 Agustus 2016 pukul 21.04 